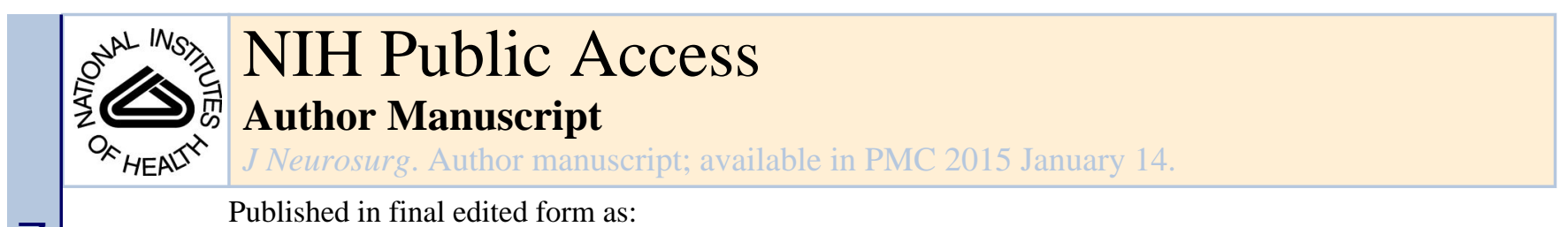

Published in final edited form as:

J Neurosurg. 2011 July ; 115(1): 30-36. doi:10.3171/2011.3.JNS091107.

\title{
Surgical management of melanoma brain metastases in patients treated with immunotherapy
}

\author{
Russell R. Lonser, M.D. ${ }^{1}$, Debbie K. Song, M.D. ${ }^{1}$, Jacob Klapper, M.D. ${ }^{2}$, Marygrace Hagan, \\ M.D. ${ }^{1}$, Sungyoung Auh, Ph.D. ${ }^{3}$, P. Benjamin Kerr, M.D. ${ }^{1}$, Deborah E. Citrin, M.D. ${ }^{4}$, John D. \\ Heiss, M.D. ${ }^{1}$, Kevin Camphausen, M.D. ${ }^{4}$, and Steven A. Rosenberg, M.D., Ph.D. ${ }^{2}$
}

${ }^{1}$ Surgical Neurology Branch, National Institute of Neurological Disorders and Stroke ${ }^{2}$ Surgery Branch, National Cancer Institute, National Institutes of Health, Bethesda, Maryland ${ }^{3}$ Office of the Clinical Director, National Institute of Neurological Disorders and Stroke ${ }^{4}$ Radiation Oncology Branch, National Cancer Institute, National Institutes of Health, Bethesda, Maryland

\begin{abstract}
Object-Despite the increasing use of immunotherapy in the treatment of metastatic melanoma, the effects of this therapy on the management of patients with associated brain metastases are not completely defined. The authors undertook this study to determine the effectiveness of resection and the effects of immunotherapy on brain metastasis management.
\end{abstract}

\begin{abstract}
Methods-The authors analyzed data pertaining to consecutive patients with metastatic melanoma treated with immunotherapy within 3 months of discovery of brain metastases that were surgically resected.
\end{abstract}

\begin{abstract}
Results-Forty-one patients (median age 44.4 years, range 19.2-63.1 years) underwent resection of 53 brain metastases (median number of metastases 1, range 1-4). The median metastasis volume was $2.5 \mathrm{~cm}^{3}$. Fifteen patients underwent whole-brain radiation therapy (WBRT) and 26 patients did not. Duration of survival from brain metastasis diagnosis was not significantly different between patients who received WBRT (mean 24.9 months) and those who did not (mean 23.3 months) ( $p>0.05)$. Local and distant brain recurrence rates were not statistically different between the WBRT (7.1\% and 28.6\%, respectively) and non-WBRT (7.7\% and $41.0 \%)$ groups for the duration of follow-up $(\mathrm{p}>0.05)$. An objective systemic response to immunotherapy was associated with increased duration of survival $(\mathrm{p}<0.05)$.
\end{abstract}

Conclusions-Resection of melanoma brain metastases in patients treated with immunotherapy provides excellent local control with low morbidity. An objective response to systemic immunotherapy is associated with a prolonged survival in patients who have undergone resection Address correspondence to: Russell R. Lonser, M.D., Surgical Neurology Branch, National Institute of Neurological Disorders and
Stroke, National Institutes of Health, Building 10, Room 3D20, Bethesda, Maryland 20892. lonserr@ninds.nih.gov.
Author contributions to the study and manuscript preparation include the following. Conception and design: Lonser, Song, Klapper.
Acquisition of data: Song, Klapper, Hagan, Auh, Kerr. Analysis and interpretation of data: Song, Klapper, Hagan, Auh. Drafting the
article: Song, Hagan, Citrin. Critically revising the article: Lonser, Citrin, Heiss, Camphausen, Rosenberg. Reviewed final version of
the manuscript and approved it for submission: all authors. Statistical analysis: Klapper, Song, Auh, Hagan. Administrative/technical/
material support: Lonser.

Disclosure

The authors report no conflict of interest concerning the materials or methods used in this study or the findings specified in this paper. 
of melanoma brain metastases. Moreover, adjuvant WBRT in melanoma immunotherapy patients with limited metastatic disease to the brain does not appear to provide a significant survival benefit.

\section{Keywords}

immunotherapy; melalloma; metastasis; radiation; surgery; oncology

$\mathrm{T}_{\text {не }}$ incidence of malignant melanoma is among the fastest rising of all cancers. ${ }^{20}$ Cutaneous melanomas that are diagnosed early can be cured with surgical excision with or without adjuvant therapy, but a large number of melanoma patients will go on to develop disseminated disease. Although it accounts for less than 5\% of cutaneous malignancies, melanoma causes $75 \%$ of skin cancer-related deaths because of complications associated with metastatic disease. ${ }^{13}$ Melanoma is one of the most common malignancies to metastasize to the brain. The prevalence of brain metastases in patients with melanoma ranges from $10 \%$ to $40 \%$ in clinical series and up to $73 \%$ in autopsy series. ${ }^{1,5,23}$ Despite early detection and improved management strategies, melanoma brain metastasis heralds a poor prognosis and is a frequent cause of death.

Because of the limited effectiveness of cytotoxic chemotherapy in treating disseminated melanoma and because melanomas are highly immunogenic cancers, immunotherapeutic treatment paradigms are being used more frequently in the management of systemic melanoma. Despite the increasing use of this biological therapy in the treatment of disseminated melanoma, little is known about its effect on brain metastases and ultimately on their management. To determine the effectiveness of resection and effects of systemic immunotherapy on the management of melanoma brain metastases, we analyzed the serial imaging and clinical findings obtained in consecutive melanoma immunotherapy patients with brain metastases that were treated surgically at the NIH.

\section{Methods}

\section{Patients}

Study Group-The study group comprised consecutive patients treated with immunotherapy for malignant melanoma who underwent craniotomy for resection of brain metastases between September 1998 and February 2007 at the NIH. Patients with surgically accessible lesions, limited systemic disease (with estimated life expectancy greater than 3 months), and/or symptomatic lesion(s) were candidates for surgery.

Clinical Analysis-Clinical data were collected via retrospective chart and imaging review. Patients were preoperatively assigned a KPS score and stratified using recursive partitioning analysis (RPA). ${ }^{14}$ The RPA classification system categorizes patients into 3 risk categories based on KPS score, status of extracranial disease, and patient age: Class 1 (age < 65 years, KPS score $\geq 70$, controlled primary disease, no extracranial metastases), Class 2 (all others with KPS score 270 ), and Class 3 (KPS score < 70). ${ }^{7}$ Detailed distant follow-up was supplemented by telephone contact with patients, family members, and/or personal physicians. 
Imaging Analysis-Preoperative MR imaging was used to determine metastasis location and to calculate tumor volume $($ volume $=$ [largest anteroposterior diameter $\times$ largest mediolateral diameter $\times$ largest dorsoventral diameter $] / 2$ ). Postoperative MR imaging was used to assess completeness of resection and to determine if there was any local or distant metastatic recurrence in the brain.

\section{Systemic Immunotherapy}

The Tumor Immunology Section of the Surgery Branch at the National Cancer Institute of the NIH treated all patients in the study for metastatic melanoma within 3 months of discovery of intracranial disease. Response to systemic immunotherapy for extracranial disease was determined using the RECIST guidelines. ${ }^{29}$ For purposes of data analysis, patients with a complete response, partial response, or stable disease were categorized in the response group. Patients with progressive disease were categorized in the no-response group.

\section{Surgical Technique}

All patients underwent 3D stereotactic contrast-enhanced MR imaging of the cerebrum the day before surgery. At surgery, frameless stereotaxy was used to precisely localize the metastasis (or metastases) and to minimize the size of the craniotomy. Intraoperative cerebral swell ing was managed with diuretics and mild transient hyperventilation (steroid agents were not used). All metastases were removed circumferentially in an en bloc fashion.

\section{Histological Analysis}

Histological analysis of resected lesions was performed to confirm the pathological diagnosis of melanoma metastatic deposits. Cases of tumor recurrence and resection were analyzed for the presence of tumor-infiltrating lymphocytes at the tumor center and periphery. The histological extent of tumor-infiltrating lymphocytes was graded as none, mild, moderate, or marked/severe.

\section{Statistical Analysis}

Survival times were calculated from the time of cerebral metastasis diagnosis. Analyses of local and distant brain recurrences following craniotomy were based on the number of resected metastases. Survival times of patients and recurrence of metastases treated with and without postoperative WBRT were estimated using Kaplan-Meier curves, and differences were compared by means of the log-rank test. A second Kaplan-Meier survival analysis was used to evaluate the differences in survival time and tumor recurrence between patients who had an objective response to systemic immunotherapy and those who did not. All cited $p$ values are 2 -sided and $\mathrm{p}$ values less than 0.05 were considered statistically significant. Statistical analyses were performed using SAS version 9.1.3 (SAS Institute, Inc.). 


\section{Results}

\section{Patient Characteristics}

General-The characteristics of the patients included in the study are listed in Table 1. A total of 41 patients ( 24 men; 17 women) who underwent resection of 53 melanoma brain metastases were included in this study. Median age at initial metastasis resection was 44.4 years (range 19.2-63.1 years). Median preoperative KPS score was 100 (range 80-100). Patients were stratified into RPA Class I (1 patient; 2.4\%) or II (40 patients [97.6\%]). Systemic immunotherapy regimens and timing of treatment are listed in Tables 2 and 3, respectively.

Response to Immunotherapy-Four patients (9.8\%) had a complete response to systemic immunotherapy, 11 (26.8\%) had a partial response, 2 (4.9\%) had stable disease, and $24(58.5 \%)$ had progressive disease according to RECIST criteria. There was no significant difference in systemic response to immunotherapy with regard to immunotherapy regimen (logistic regression analysis, $\mathrm{p}>0.05$ ) or intracranial tumor burden (logistic regression analysis, $\mathrm{p}>0.05$ ). Furthermore, there was no significant difference (Fisher exact test, $p>0.05$ ) between timing of immunotherapy in relation to metastasis resection and systemic response to immunotherapy.

Whole-Brain Radiation Therapy-Fifteen patients (36.6\%) underwent adjuvant WBRT (dose range, 3000- $4000 \mathrm{cGy}$ ) and 26 (63.4\%) did not receive WBRT. Characteristics of these 2 groups of patients were not significantly different (Table 4). Similarly, the characteristics of tumors not treated with WBRT and tumors that were treated with WBRT were not significantly different (Table 5). Postoperative WBRT was administered following resection of 14 cerebral metastases in 11 patients. Four patients were given WBRT after detection of a distant metastatic cerebral recurrence.

Stereotactic Radiosurgery-Five patients (12.2\%) underwent SRS to 5 melanoma brain metastases before resection. Four of these patients required resection of the SRS-treated metastasis due to local failure. Three of the 4 resected metastases were associated with hemorrhage and significant mass effect. One patient underwent successful SRS of a single metastasis but entered the study after resection of a new metastasis that developed at a separate accessible site.

\section{Tumor Characteristics}

En bloc gross-total resection of all 53 surgically treated metastases was achieved and confirmed on postoperative MR images. The median resected metastasis volume was 2.5 $\mathrm{cm}^{3}$ (range $0.1-35.3 \mathrm{~cm}^{3}$ ). One metastasis (1.9\%) was located in the cerebellum, while the remaining 52 metastases were supratentorial. Supratentorial metastases were located in the frontal (22 metastases [41.5\% of all metastases resected]), parietal (19 [35.8\%]), occipital (6 [11.3\%]), or temporal lobes (5 [9.4\%]). Two patients (2 metastases [4\%]) had a single metastasis in the primary motor cortex. Fourteen metastases (26.4\%) showed imaging evidence of hemorrhage at presentation. Thirty-two patients (78.0\%) underwent resection of a single metastasis, 7 patients (17.1\%) underwent resection of 2 metastases ( 2 operations 
each), 1 patient (2.4\%) underwent resection of 3 metastases ( 2 operations), and 1 patient $(2.4 \%)$ underwent resection of 4 metastases ( 3 operations).

\section{Survival Analysis}

All patients survived more than 2 months after resection of intracranial metastasis. Overall, the mean duration of survival from the time of brain metastasis diagnosis was 23.9 months (median 16.1 months, range 2.3-95.2 months). The mean duration of survival from the time of initial metastasis resection was 21.6 months (median 12.4 months, range 2.2-95.0 months). The mean duration of survival after cerebral metastasis diagnosis for patients who did not receive WBRT was 23.3 months (median 12.2 months, range 2.3-95.2 months) and was similar to the mean value of 24.9 months for those who received adjuvant WBRT (median 19.1 months, range 4.2-64.7 months) $(\mathrm{p}=0.65)$.

Patients who had an objective response to systemic immunotherapy had significantly $(\mathrm{p}=$ 0.02) longer mean survival (mean 33.8 months, range 3.5-75.9 months) than patients who did not respond to immunotherapy (mean 16.6 months, range 2.3-95.2 months) (Fig. 1). The 6-month survival rate following initial metastasis resection was $88.2 \%$ in immunotherapy responders and $62.5 \%$ in nonresponders $(\mathrm{p}=0.09)$. The 12 -month survival rate following resection was $70.6 \%$ in immunotherapy responders and $37.5 \%$ in nonresponders $(p=0.06)$.

\section{Intracerebral Recurrence}

There were 20 distant recurrences and 4 local recurrences in these patients. Fifteen patients had 1 distant recurrence, 2 patients each developed 2 distant recurrences after 2 different tumor resections, 3 patients had a single local recurrence, and 1 patient had both a single distant and a single local recurrence. Whole-brain radiation therapy was administered following resection of 14 metastases; 39 metastases were not subjected to postoperative WBRT. There was no statistically significant difference between WBRT-treated tumors $(35.7 \%)$ and non-WBRT treated tumors $(48.7 \%, \mathrm{p}=0.36)$ with respect to the overall rate of recurrence in the brain.

Local Recurrence-There were 4 local recurrences in 4 patients following resection. The overall local control rate was $92.5 \%$. Among the 39 metastases that were not subjected to adjuvant WBRT, there were 3 local recurrences (7.7\% of metastases resected in this group). There was 1 local recurrence among the 14 tumors that were subjected to postoperative WBRT ( $7.1 \%$ of resected metastases in this group). There was no statistically significant difference in the time to local recurrence among tumors that had or had not been subjected to postoperative WBRT ( $\mathrm{p}=0.86$ ). In the non-WBRT group of metastases, the mean time to local recurrence was 18.1 months after initial resection (median 10.2 months, range 1.5-95.0 months). The mean time to local recurrence in the WBRT group was 18.8 months (median 16.4 months, range 2.7-64.6 months).

Distant Recurrence-Overall, there were 20 distant metastatic recurrences in 18 patients. The distant recurrence rate was $37.7 \%$ for all of the metastases resected. Sixteen distant metastatic recurrences occurred following the resection of 39 metastases in the non-WBRT group ( $41.0 \%$ of the metastases in this group). Of the 14 resected metastases in the WBRT 
tumor group, there were 4 distant recurrences that occurred (28.6\% of the metastases in this group). The difference between the WBRT and non-WBRT tumor groups with respect to incidence of or time to distant recurrence was not statistically significant $(p=0.25)$.

\section{Clinical Outcome}

Based on MR imaging, 36 patients (88\%) were rendered free of intracranial metastatic disease after resection. Four patients had large symptomatic metastases that were resected but also had small, deep, asymptomatic metastases that were treated with SRS. One patient had numerous metastatic lesions (more than 10) but underwent resection of a large symptomatic metastasis that had progressed after SRS. All patients were neurologically stable or improved at time of discharge. One patient (representing $2 \%$ of operations) had a postoperative epidural hematoma associated with headache that was evacuated 8 days after metastasis resection without further sequelae.

\section{Histological Findings}

The results of histological examination were consistent with melanoma metastasis in every case. The 4 metastases that represented local recurrences and were reresected were examined for evidence of tumor-infiltrating lymphocytes at the tumor periphery and center. While 1 of the metastases had evidence of a mild lymphocyte response at the tumor center and a moderate to severe response at the periphery, the remaining 3 metastases had no evidence of a lymphocyte response at the tumor center and showed a mild response at the periphery.

\section{Discussion}

\section{Immunotherapy for Melanoma}

Unlike cytotoxic chemotherapeutic treatment regimens, immunotherapy strategies exploit the body's ability to recognize and destroy abnormal immunogenic melanoma cells. The most commonly used immune-modulatory therapy for metastatic melanoma is high-dose IL-2 (Table 3). This treatment was approved by the US Food and Drug Administration for the treatment of metastatic melanoma or renal cell carcinoma in $1998 .{ }^{26}$ Interleukin-2 is a cytokine that enhances the body's immune system via stimulation of T-lymphocytes. Studies examining the effectiveness of high-dose IL-2 alone or in combination with other tumortargeted immune-enhancing therapies have demonstrated response rates of up to $22 \%$, and durable remissions can persist for several years leading to long-term survival in some patients. $3,21,26$

Although the brain has traditionally been considered an immune-privileged site, studies demonstrating regression of melanoma brain metastases in patients treated with systemic immunotherapy indicate a potential biological effect in the central nervous system for this form of treatment. Specifically, Guirguis et al., ${ }^{9}$ Rosenberg et al., ${ }^{22}$ and Hong et al. ${ }^{11}$ have found that some melanoma patients harboring cerebral metastases treated with IL-2 in combination with other immunotherapy modalities demonstrated an objective responsewith respect to brain metastasis - to systemic immunotherapy. To define the effectiveness of resection and to gain deeper insight into the effects of systemic immunotherapy in the 
management of brain metastases, we studied consecutive melanoma patients who were treated with systemic immunotherapy and who underwent resection of cerebral metastases.

\section{Clinical Implications}

Resection or SRS in Immunotherapy-Because corticosteroids may impair the effectiveness of systemic immunotherapeutic treatment strategies, in patients undergoing immunotherapy, it may be preferable to manage brain metastases in a manner that minimizes or avoids the use of these medications. Because SRS of brain metastases has been associated with increased peritumoral edema and/or radiation necrosis, ${ }^{15}$ steroid therapy is often necessary for patients undergoing or following SRS. The findings of the current study indicate that resection eliminates the source of edema (the metastasis), results in the rapid amelioration of peritumoral edema, and obviates the need for steroid use. Moreover, because of the transient vascular leak syndrome that can occur with high-dose IL-2 therapy, intracranial treatment strategies to minimize peritumoral edema are important in this patient population.

Intratumoral hemorrhage is a frequent complication of SRS for melanoma brain metastases that can exacerbate edema and create additional mass effect that may require steroid treatment or surgery. ${ }^{15,19}$ Mathieu et al. ${ }^{15}$ analyzed data from 244 melanoma patients who underwent SRS treatment of 754 intracerebral melanoma metastases and found that $22 \%$ of patients had radiographic evidence of intratumoral hemorrhage. Fifty-nine percent of these patients suffered acute deterioration in their neurological status, resulting in the need for craniotomy for evacuation of intracerebral hemorrhage in $28 \%$ of patients and death in another $20 \%$ of patients. The results of the present study indicate that resection of melanoma metastases may be achieved safely in patients undergoing immunotherapy. Avoiding the SRS-associated risk of intratumoral hemorrhage might be particularly important in immunotherapy patients, who may be at increased risk of hemorrhage during a thrombocytopenic phase of treatment.

Effectiveness of Resection-The effectiveness of focal therapy in the management of cerebral metastasis is measured by local control. Specifically, en bloc resection was performed in each case to minimize the risk of local recurrence ${ }^{17}$ and leptomeningeal dissemination. ${ }^{27,28}$ Resection of melanoma metastases in this immunotherapy series resulted in a local control rate of $92.5 \%$, which compares favorably to the local control rates reported in other series after brain metastasis resection (54\%-88\% local control rate) $)^{4,16}$ and SRS (49\%-86\% local control rate). ${ }^{8,15,18,24}$

Immunotherapy and Brain Metastases-Data from the current series indicate that response to systemic immunotherapy is associated with increased duration of survival (Fig. 1). Previously, Hurst et al. ${ }^{12}$ reviewed outcomes in 36 patients who developed a single brain metastasis (either metastatic melanoma or renal cell carcinoma) after treatment with highdose IL-2. All the patients underwent resection of the brain metastasis, and $86 \%$ of the patients underwent postoperative WBRT. Despite patient population differences (number of metastases, relationship of immune therapy treatment to metastasis development, and histological characteristics) between the series of Hurst et al. ${ }^{12}$ and the current series, the 
studies are similar in demonstrating that response to systemic immunotherapy was associated with longer survival.

Role of WBRT-While previous studies have analyzed the effects of WBRT after surgical treatment of metastatic tumors of heterogeneous histological types, ${ }^{2,16}$ few studies have specifically examined the effects of WBRT in the management of melanoma brain metastasis after resection and none of these have involved patients treated with immunotherapy (Table 6). ${ }^{6,10,23,25,31}$ Similar to the current study, these previous studies have not shown a survival benefit for WBRT after resection (Table 6). Moreover, although the sample size was small in the present study, there was not a significant reduction in recurrence (local or distant) associated with postresection WBRT in patients treated with immunotherapy.

Resection in Immunotherapy Patients-While findings from the current series could be biased because of the retrospective nature of the study, patient involvement in one or more clinical trials, and varied immunotherapy regimens, this study provides direct insight into the ability of immunotherapy to affect systemic disease control, intracranial tumor burden, recurrence and survival. Data from the current series indicate that resection of intracranial melanoma metastases in patients treated with immunotherapy provides an excellent management option associated with minimal morbidity and excellent control. Specifically, patients with surgically accessible lesions, limited disease, and an expected duration of survival greater than 3 months may be optimal surgical candidates. Because of the unique features associated with systemic immunotherapy and potential complications associated with SRS in relationship to immunotherapy,${ }^{30}$ surgical excision of cerebral metastases provides a management advantage over SRS. Specifically, complete resection of the metastatic deposit eliminates it as a source of edema that is often associated with the need for steroids after radiation treatment—particularly in the context of immunotherapyrelated vascular leak syndrome. Moreover, resection eliminates the metastasis as a source of hemorrhage, which could be especially problematic in patients with immunotherapyassociated thrombocytopenia.

\section{Conclusions}

Resection of melanoma brain metastases in patients treated with immunotherapy provides excellent local control with low morbidity. An objective response to systemic immunotherapy is associated with a prolonged survival in patients who have undergone resection of melanoma brain metastases. Moreover, adjuvant WBRT does not appear to provide a significant survival benefit in melanoma patients who are treated with immunotherapy and have limited metastatic disease to the brain.

\section{Acknowledgments}

This research was supported by the Intramural Research Programs of the National Institute of Neurologic Disorders and Stroke and the National Cancer Institute at the NIH. 


\section{Abbreviations}

$\begin{array}{ll}\text { IL-2 } & \text { interleukin-2 } \\ \text { KPS } & \text { Kamofsky Performance Scale } \\ \text { NIH } & \text { National Institutes of Health } \\ \text { RPA } & \text { recursive partitioning analysis } \\ \text { REOST } & \text { Response Evaluation Criteria in Solid Tumors } \\ \text { SRS } & \text { stereotactic radiosurgeiy } \\ \text { WBRT } & \text { whole-brain radiation therapy }\end{array}$

\section{References}

1. Amer MH, Al-Sarraf M, Vaitkevicius VK. Clinical presentation, natural history and prognostic factors in advanced malignant melanoma. Surg Gynecol Obstet. 1979; 149:687-692. [PubMed: 505243]

2. Aoyama H, Shirato H, Tago M, Nakagawa K, Toyoda T, Hatano K, et al. Stereotactic radiosurgery plus whole-brain radiation therapy vs stereotactic radiosurgery alone for treatment of brain metastases: a randomized controlled trial. JAMA. 2006; 295:2483-2491. [PubMed: 16757720]

3. Atkins MB, Lotze MT, Dutcher JP, Fisher RI, Weiss G, Margolin K, et al. High-dose recombinant interleukin 2 therapy for patients with metastatic melanoma: analysis of 270 patients treated between 1985 and 1993. J Clin Oncol. 1999; 17:2105-2116. [PubMed: 10561265]

4. Brega K, Robinson WA, Winston K, Wittenberg W. Surgical treatment of brain metastases in malignant melanoma. Cancer. 1990; 66:2105-2110. [PubMed: 2224765]

5. de la Monte SM, Moore GW, Hutchins GM. Patterned distribution of metastases from malignant melanoma in humans. Cancer Res. 1983; 43:3427-3433. [PubMed: 6850649]

6. Fife KM, Colman MH, Stevens GN, Firth IC, Moon D, Shannon KF, et al. Determinants of outcome in melanoma patients with cerebral metastases. J Clin Oncol. 2004; 22:1293-1300. [PubMed: 15051777]

7. Gaspar L, Scott C, Rotman M, Asbell S, Phillips T, Wasserman T, et al. Recursive partitioning analysis (RPA) of prognostic factors in three Radiation Therapy Oncology Group (RTOG) brain metastases trials. Int J Radiat Oncol Biol Phys. 1997; 37:745-751. [PubMed: 9128946]

8. Gieger M, Wu JK, Ling MN, Wazer D, Tsai JS, Engler MJ. Response of intracranial melanoma metastases to stereotactic radiosurgery. Radiat Oncol Investig. 1997; 5:72-80.

9. Guirguis LM, Yang JC, White DE, Steinberg SM, Liewehr DJ, Rosenberg SA, et al. Safety and efficacy of high-dose interleukin-2 therapy in patients with brain metastases. J Immunother. 2002; 25:82-87. [PubMed: 11924913]

10. Hagen NA, Cirrincione C, Thaler HT, DeAngelis LM. The role of radiation therapy following resection of single brain metastasis from melanoma. Neurology. 1990; 40:158-160. [PubMed: 2296364]

11. Hong JJ, Rosenberg SA, Dudley ME, Yang JC, White DE, Butman JA, et al. Successful treatment of melanoma brain metastases with adoptive cell therapy. Clin Cancer Res. 2010; 16:4892-4898. [PubMed: 20719934]

12. Hurst R, White DE, Heiss J, Lee DS, Rosenberg SA, Schwartzentruber DJ. Brain metastasis after immunotherapy in patients with metastatic melanoma or renal cell cancer: is craniotomy indicated? J Immunother. 1999; 22:356-362. [PubMed: 10404437]

13. Jemal A, Siegel R, Ward E, Hao Y, Xu J, Murray T, et al. Cancer statistics, 2008. CA Cancer J Clin. 2008; 58:71-96. [PubMed: 18287387]

14. Karnofsky DA, Abelmann WH, Craver LF, Burchenal JH. The use of nitrogen mustards in the palliative treatment of carcinoma. Cancer. 1948; 1:634-656. 
15. Mathieu D, Kondziolka D, Cooper PB, Flickinger JC, Niranjan A, Agarwala S, et al. Gamma knife radiosurgery in the management of malignant melanoma brain metastases. Neurosurgery. 2007; 60:471-472. [PubMed: 17327791]

16. Patchell RA, Tibbs PA, Regine WF, Dempsey RJ, Mohiuddin M, Kryscio RJ, et al. Postoperative radiotherapy in the treatment of single metastases to the brain: a randomized trial. JAMA. 1998; 280:1485-1489. [PubMed: 9809728]

17. Patel AJ, Suki D, Hatiboglu MA, Abouassi H, Shi W, Wildrick DM, et al. Factors influencing the risk of local recurrence after resection of a single brain metastasis. Clinical article. J Neurosurg. 2010; 113:181-189. [PubMed: 20035574]

18. Radbill AE, Fiveash JF, Falkenberg ET, Guthrie BL, Young PE, Meleth S, et al. Initial treatment of melanoma brain metastases using gamma knife radiosurgery: an evaluation of efficacy and toxicity. Cancer. 2004; 101:825-833. [PubMed: 15305416]

19. Redmond AJ, Diluna ML, Hebert R, Moliterno JA, Desai R, Knisely JP, et al. Gamma Knife surgery for the treatment of melanoma metastases: the effect of intratumoral hemorrhage on survival. J Neurosurg. 2008; 109:99-105. Suppl. [PubMed: 19123895]

20. Rigel DS, Carucci JA. Malignant melanoma: prevention, early detection, and treatment in the 21 st century. CA Cancer J Clin. 2000; 50:215-240. [PubMed: 10986965]

21. Riker AI, Radfar S, Liu S, Wang Y, Khong HT. Immunotherapy of melanoma: a critical review of current concepts and future strategies. Expert Opin Biol Ther. 2007; 7:345-358. [PubMed: 17309326]

22. Rosenberg SA, Yang JC, Schwartzentruber DJ, Hwu P, Marincola FM, Topalian SL, et al. Immunologic and therapeutic evaluation of a synthetic peptide vaccine for the treatment of patients with metastatic melanoma. Nat Med. 1998; 4:321-327. [PubMed: 9500606]

23. Sampson JH, Carter JH Jr, Friedman AH, Seigler HF. Demographics, prognosis, and therapy in 702 patients with brain metastases from malignant melanoma. J Neurosurg. 1998; 88:11-20. [PubMed: 9420067]

24. Selek U, Chang EL, Hassenbusch SJ III, Shiu AS, Lang FF, Allen P, et al. Stereotactic radiosurgical treatment in 103 patients for 153 cerebral melanoma metastases. Int J Radiat Oncol Biol Phys. 2004; 59:1097-1106. [PubMed: 15234044]

25. Skibber JM, Soong SJ, Austin L, Balch CM, Sawaya RE. Cranial irradiation after surgical excision of brain metastases in melanoma patients. Ann Surg Oncol. 1996; 3:118-123. [PubMed: 8646510]

26. Smith FO, Downey SG, Klapper JA, Yang JC, Sherry RM, Royal RE, et al. Treatment of metastatic melanoma using interleukin-2 alone or in conjunction with vaccines. Clin Cancer Res. 2008; 14:5610-5618. [PubMed: 18765555]

27. Suki D, Abouassi H, Patel AJ, Sawaya R, Weinberg JS, Groves MD. Comparative risk of leptomeningeal disease after resection or stereotactic radiosurgery for solid tumor metastasis to the posterior fossa. J Neurosurg. 2008; 108:248-257. [PubMed: 18240919]

28. Suki D, Hatiboglu MA, Patel AJ, Weinberg JS, Groves MD, Mahajan A, et al. Comparative risk of leptomeningeal dissemination of cancer after surgery or stereotactic radiosurgery for a single supratentorial solid tumor metastasis. Neurosurgery. 2009; 64:664-666. [PubMed: 19197219]

29. Therasse P, Arbuck SG, Eisenhauer EA, Wanders J, Kaplan RS, Rubinstein L, et al. New guidelines to evaluate the response to treatment in solid tumors. European Organization for Research and Treatment of Cancer, National Cancer Institute of the United States, National Cancer Institute of Canada. J Natl Cancer Inst. 2000; 92:205-216. [PubMed: 10655437]

30. Williams BJ, Suki D, Fox BD, Pelloski CE, Maldaun MV, Sawaya RE, et al. Stereotactic radiosurgery for metastatic brain tumors: a comprehensive review of complications. Clinical article. J Neurosurg. 2009; 111:439-448. [PubMed: 19301968]

31. Wronski M, Arbit E. Surgical treatment of brain metastases from melanoma: a retrospective study of 91 patients. J Neurosurg. 2000; 93:9-18. [PubMed: 10883899] 


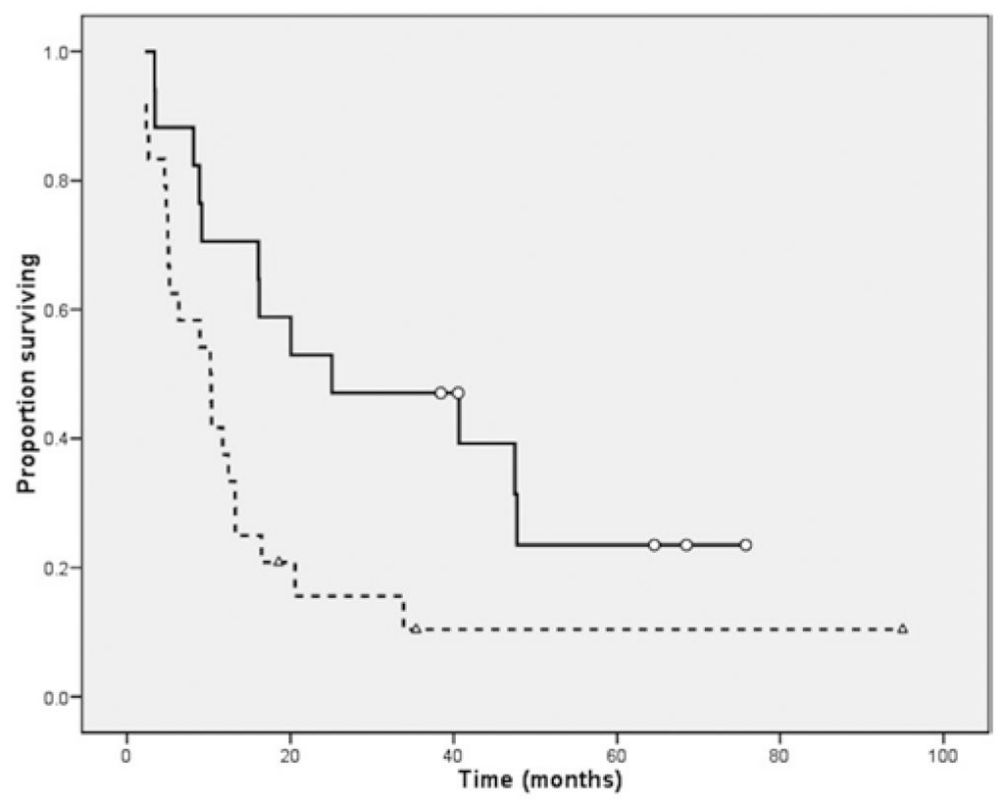

Fig. 1.

Kaplan-Meier survival curves for patients who had a clinical response to systemic immunotherapy (solid line) and those who did not (dashed line). The difference was significant (log-rank test, $\mathrm{p}<0.05)$. 


\section{TABLE 1}

Patient characteristics

\begin{tabular}{|c|c|}
\hline Characteristic & Value* \\
\hline \multicolumn{2}{|l|}{ age at initial resection (yrs) } \\
\hline median & 44.4 \\
\hline range & $19.2-63.1$ \\
\hline \multicolumn{2}{|l|}{$\operatorname{sex}$} \\
\hline male & $24(58.5)$ \\
\hline female & $17(41.5)$ \\
\hline \multicolumn{2}{|l|}{ KPS score } \\
\hline 100 & $28(68.3)$ \\
\hline 90 & $8(19.5)$ \\
\hline 80 & $5(12.2)$ \\
\hline \multicolumn{2}{|l|}{ RPA class } \\
\hline I & $1(2.4)$ \\
\hline II & $40(97.6)$ \\
\hline \multicolumn{2}{|c|}{ response to immunotherapy } \\
\hline responders & $17(41.5)$ \\
\hline complete & $4(9.8)$ \\
\hline partial & $11(26.8)$ \\
\hline stable disease & $2(4.9)$ \\
\hline \multicolumn{2}{|l|}{ nonresponders } \\
\hline progressive disease & $24(58.5)$ \\
\hline WBRT & $15(36.6)$ \\
\hline
\end{tabular}




\section{TABLE 2}

Immunotherapy regimens*

\begin{tabular}{lc}
\hline \multicolumn{1}{c}{ Group \& Subgroup } & No. of Pts \\
\hline IL-2 & 35 \\
IL-2 \& vaccine & 10 \\
IL-2 \& ACT & 9 \\
IL-2, vaccine, \& ACT & 9 \\
IL-2, vaccine, \& MAb & 3 \\
IL-2 only & 1 \\
IL-2, IL-12, vaccine, \& ACT & 1 \\
immunotoxin, IL-2, \& vaccine & 1 \\
immunotoxin, IL-2, \& MAb & 1 \\
vaccine & 5 \\
vaccine only & 3 \\
vaccine \& MAb & 2 \\
MAb (MAb only) & 1 \\
\hline * & \\
ACT = adoptive cell therapy; MAb = monoclonal antibody; Pts = Patients.
\end{tabular}


TABLE 3

Timing of immunotherapy with respect to resection of cerebral metastasis

\begin{tabular}{lc}
\hline \multicolumn{1}{c}{ Timing } & No. of Pts (\%) \\
\hline immunotherapy before surgery & $19(46)$ \\
immunotherapy after surgery & $7(17)$ \\
immunotherapy before and after surgery & $15(37)$ \\
\hline
\end{tabular}




\section{TABLE 4}

Univariate analysis of patient characteristics in patients not treated with WBRT and those treated with WBRT*

\begin{tabular}{lccc}
\hline \multicolumn{1}{c}{ Characteristic } & $\begin{array}{c}\text { No WBRT } \\
(\mathbf{2 6} \text { pts) }\end{array}$ & $\begin{array}{c}\text { WBRT } \\
(\mathbf{1 5} \text { pts })\end{array}$ & p Value \\
\hline death & $20(76.9)$ & $13(86.7)$ & 0.6868 \\
sex (male) & $14(53.8)$ & $10(66.7)$ & 0.5194 \\
no response to immunotherapy & $17(65.4)$ & $7(46.7)$ & 0.3281 \\
preop SRS & $3(11.5)$ & $2(13.3)$ & 1.0000 \\
multiple tumors at entry & $7(26.9)$ & $5(33.3)$ & 0.7300 \\
preop KPS score <100 & $9(34.6)$ & $4(26.7)$ & 0.7337 \\
mean age in yrs & 44.14 & 44.23 & 0.9186 \\
\hline
\end{tabular}

* Values represent numbers of patients (\%) unless otherwise indicated. Reported p-values are 2-sided from either the Fisher exact test or Student ttest, as appropriate. 


\section{TABLE 5}

Univariate analysis of tumor characteristics in tumors not treated with WBRT and those treated with WBRT

\begin{tabular}{lccc}
\hline \multicolumn{1}{c}{ Characteristics } & $\begin{array}{c}\text { No WBRT } \\
\text { (39 tumors) }\end{array}$ & $\begin{array}{c}\text { WBRT } \\
\text { (14 tumors) }\end{array}$ & p Value \\
\hline side of tumor (right) & $22(56.4)$ & $5(35.7)$ & 0.1350 \\
supratentorial & $39(100.0)$ & $13(92.9)$ & 0.2830 \\
local recurrence & $3(7.69)$ & $1(7.1)$ & 1.0000 \\
distant recurrence & $16(41.0)$ & $4(28.6)$ & 0.3590 \\
any recurrence & $19(48.7)$ & $5(35.7)$ & 0.3630 \\
\hline
\end{tabular}

* Values represent numbers of tumors (\%) unless otherwise indicated. Reported p-values are 2-sided from either the Fisher exact test or Student ttest, as appropriate. 


\section{TABLE 6}

Median survival from series of patients with melanoma brain metastases treated with resection alone or in combination with postoperative adjuvant WBRT

\begin{tabular}{lccc}
\hline \multicolumn{1}{c}{ Authors \& Year } & $\begin{array}{c}\text { Resection Only } \\
\text { (no. of pts) }\end{array}$ & $\begin{array}{c}\text { Resection \& } \\
\text { Postop WBRT } \\
\text { (no. of pts) }\end{array}$ & $\begin{array}{c}\text { Statistically } \\
\text { Significant } \\
\text { Difference }\end{array}$ \\
\hline Fife et al., 2004 & $8.7 \operatorname{mos}(47)$ & $8.9 \operatorname{mos}(158)$ & no \\
Sampson et al., 1998 & $6.5 \operatorname{mos}(52)$ & $8.9 \operatorname{mos}(87)$ & no \\
Wronski \& Arbit, 2000 & $8.3 \operatorname{mos}(29)$ & $9.5 \operatorname{mos}(49)$ & no \\
Hagen et al., 1990 & $8.3 \operatorname{mos}(16)$ & $6.4 \operatorname{mos}(19)$ & no \\
Skibber et al., 1996 & $6 \operatorname{mos}(12)$ & $18 \operatorname{mos}(22)$ & yes \\
\hline
\end{tabular}

